\title{
Eye movement latencies for parafoveally presented words
}

\author{
KEITH RAYNER \\ Center for Visual Science, University of Rochester, Rochester, New York 14627
}

\begin{abstract}
Subjects in the present experiment made saccadic eye movements to words presented left and right of fixation. The words were presented in the range that approximates the distance covered by the eye during reading. The mean latencies were 30-100 msec shorter than mean fixation durations in reading. Latencies were significantly shorter for left-to-right saccades than for right-to-left saccades. There were also differences in saccadic latency as a function of task demands.
\end{abstract}

During reading the eyes execute saccadic eye movements mainly in a left-to-right direction for readers of English. The mean extent of the saccade is about eight character spaces (or about 2 deg of visual angle) and the mean duration of the intersaccadic fixation pause is $200-250 \mathrm{msec}$. However, these values are averages and there is a great deal of variability for a single subject reading a single passage of text such that the saccade extents range between 1 and 20 character positions and the fixation durations range from 100 to over 500 msec (Rayner \& McConkie, 1976).

Studies of saccadic latency are important for an understanding of the reading process, since it is often assumed that latencies are too long (about $200 \mathrm{msec}$, cf. Woodworth, 1938), in relation to the mean fixation time, for eye fixations to be determined on a moment-to-moment basis (Haber \& Hershenson, 1973; Walton, 1964). Unfortunately, most of the studies of saccadic latency have studied latencies as a function of visual angles that are much larger than the distance the eye typically traverses in normal reading. These studies (Baloh \& Honrubia, 1976; Bartz, 1962; Robinson, Koth, \& Ringenbach, 1976; White, Eason, \& Bartlett, 1962) have typically investigated latency as a function of exposure of a target displaced somewhere between 5 and $40 \mathrm{deg}$ from fixation. Studies which have investigated saccadic latency in the range that eye movements are typically made during reading have utilized single dots as targets (Saslow, 1967). A single dot may be more difficult to locate in the visual field than a word and, hence, longer latencies may be expected for dots than for words. Miller (1969) did use words as stimuli, but the words were displaced either 6 or $13 \mathrm{deg}$ from fixation and were thus again beyond the typical range of saccades in reading. Early studies (see Miles, 1936, for a summary)

This research was supported by Grant BNS76-05017 from the National Science Foundation. Requests for reprints should be addressed to Keith Rayner, 528 Lattimore Hall, University of Rochester, Rochester, New York 14627. are also susceptible to the criticisms mentioned above or, in cases where latencies were determined for words 1.6 deg from fixation, no differentiation was made between saccades to the left and those to the right (Dodge, 1907; Miles, 1936). In short, while there is a considerable amount of data available concerning saccadic latency, much of it may be irrelevant for reading since (1) the range over which the saccade extended was larger than the range of saccade extents in reading, (2) dots rather than words were used as stimuli, or (3) saccades to the left and to the right were not differentiated.

Eye movement latency data have also been used recently in the study of dyslexia (Dossetor \& Papaioannou, 1975; Lesevre, 1964, 1968). As with the studies of simple latency time, the data are not unambiguous. For example, Dossetor and Papaioannou (1975) reported that dyslexic subjects moved their eyes faster to a target dot 40 deg to the right of fixation than to a dot $40 \mathrm{deg}$ to the left of fixation. Skilled readers, on the other hand, moved their eyes faster to the left of fixation than to the right. Such data are inconsistent with data reported by Lesevre (1964, 1968). She found that skilled readers moved their eyes faster to targets to the right of fixation than to the left; dyslexics showed no asymmetry. One problem with the Dossetor and Papaioannou data is that the mean latency period for a 40 -deg saccade $(440 \mathrm{msec})$ was considerably longer than latencies (about $250-275 \mathrm{msec}$ ) typically found for excursions of that magnitude (Bartz, 1962; White et al., 1962). It seems reasonable that, if skilled readers have any asymmetry in saccadic latency, the latency should be shorter for a left-to-right movement since about $90 \%$ of the saccades in reading are in that direction.

In the present experiment, subjects made saccadic eye movements to word targets presented in the range that approximates the distance covered by the eye in normal reading. Latencies, saccade durations, and naming times for words presented left and right of a central fixation point were recorded in order to more 
precisely determine the characteristics of the reaction time of the eye in a situation more analogous to reading than most prior experiments have provided.

\section{METHOD}

\section{Subjects}

Six skilled readers with normal uncorrected vision volunteered to serve as subjects. All were right-handed and all but one had considerable experience as subjects in eye movement experiments.

\section{Materials and Apparatus}

Thirty words with word frequency counts between 38 and 60 in the Kučera and Francis (1967) corpus were displayed on a VT-11 cathode ray tube (CRT) which was interfaced with a PDP-11 computer. One third of the words were five letters long, another third were six, and the remainder were seven letters. The subject's eye was $48 \mathrm{~cm}$ from the face of the CRT and three character spaces equaled $1 \mathrm{deg}$ of visual angle. Words appeared beginning 1,3 , or 5 deg to the right of a central fixation point or ending 1,3 , or 5 deg to the left of the fixation point. Each word occurred equally often in each of six locations in a randomly determined manner.

Eye movements were recorded by an infrared sensing device (Biometrics Model SG with filter removed), and horizontal saccades were monitored from the right eye. The eye movement recorder was interfaced with the computer and the signal from the eye sensors was sampled every millisecond. Subjects rested their heads against a forehead rest, but a bitebar was not necessary. Since the subjects were practiced in the task, they were able to keep their heads relatively still for a block of 30 trials. Naming times for each word were recorded via a throat-activated microphone which was also interfaced with the computer.

\section{Procedure}

When a subject arrived for the experiment, the microphone, headrest, and eye sensors were adjusted. Subjects were then given 30-60 warm-up trials. Initially, five calibration dots appeared horizontally on the CRT and the subject fixated each dot and pushed a button held in the right hand. Careful initial adjustment of the sensors and instructions to the subjects to carefully fixate each dot usually resulted in satisfactory calibration patterns in one or two tries.

Each block consisted of 30 trials in which each word appeared once. Initially, a fixation dot appeared in the center of the CRT and the subject pushed a button while fixating the dot. If the subject was fixated within $1 / 2$ character space left or right of the fixation dot, a word appeared at one of the six parafoveal locations. Subjects were instructed to move their eyes to the location of the parafoveally presented word and name it as rapidly as possible. Naming of the word resulted in its disappearance from the CRT and the reappearance of the fixation dot, thus initiating a new cycle. If the subject was not fixated within a specified region as he pushed the button, the computer made a loud beeping noise and the subject then refixated the dot and pushed the button. Trials in which the latency was less than $100 \mathrm{msec}$ and/or the saccade was completed in less than $15 \mathrm{msec}$ were excluded from the data analysis and automatically repeated later in the block. Pilot work with the apparatus indicated that trials with very short latencies and/or short saccade durations were characteristic of drifts of the eye rather than saccades.

\section{RESULTS}

Table 1 shows the results of the experiment. The number of blocks of trials per subject varied somewhat, but each mean for each subject in Table 1 was based on 30-90 data points. Separate 2 (left vs. right) by 3 (visual angle) analyses of variance were carried out on the dependent variables of saccadic latency, saccade duration, and naming time. The latter variable was based on the amount of time that elapsed from the end of the saccade to the beginning of the utterance.

As seen in Table 1, saccadic latency and saccade duration times were shorter for words presented to the right of fixation than for words presented to the left. The shorter saccade duration for words to the right of fixation was apparently due to the fact that subjects had to move their eyes farther to the left of fixation to bring the fovea onto the beginning of the word.

Newman-Keuls tests (Winer, 1971) on the main effect of visual angle yielded similar patterns for the saccade duration and naming time data. These tests indicated that for the saccade duration data the means for each of the visual angles were significantly different from each other. For the naming time data, the means at 1 and 3 deg did not differ from each other, nor did the means at 3 and 5 deg differ from each other. For the saccadic latency data, latencies for words presented 1 deg from fixation were longer than latencies for words presented 3 and 5 deg from fixation, which did not differ from each other.

In addition to providing data presented in Table 1 , four of the subjects participated in experiments (Rayner, 1978) dealing with parafoveal vision, where saccadic latencies were determined using the same apparatus. In one experiment, subjects fixated on an initial fixation dot and a word or letter string appeared in parafoveal vision. Subjects were instructed to make a saccade to the location of the word; while the eye was in motion the computer replaced the first stimulus with another word. Thus, on half of the trials, when the eye arrived at its destination there was a different word present than when the saccade began. The task was to make a same-different judgment. In a second experiment, the situation was very similar (i.e., changes in the word location during the saccade) except the task was to name the second word as rapidly as possible. Since four of the subjects participated in both experiments, it was possible to compare latencies as a function of task demands.

The relationship between the characteristics of the initially displayed word and the word present after the display change was identical in both tasks. However, in the same-different task words were presented only to the right of fixation, while in the naming task stimuli were presented right and left of fixation. An initial analysis revealed no differences in mean latencies as a function of the type of initially displayed alternative; therefore, mean latencies were determined as a function of task and visual angle for all saccades to the right of fixation for the four subjects. Table 2 shows the results. There was a significant 
Table 1

Saccadic Latency, Saccade Duration, and Naming Time for Each Subject in Milliseconds

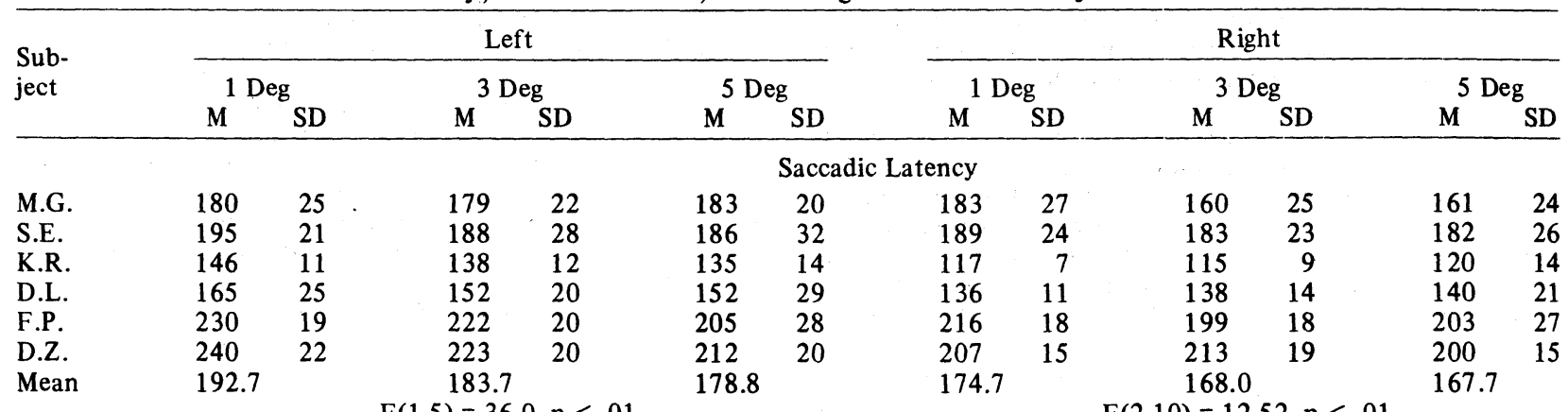

$\begin{array}{lll}\text { M.G. } & 28 & 3 \\ \text { S.E. } & 25 & 6 \\ \text { K.R. } & 25 & 3 \\ \text { D.L. } & 24 & 5 \\ \text { F.P. } & 21 & 3 \\ \text { D.Z. } & 20 & 3 \\ \text { Mean } & 23.8 & \end{array}$

M.G.

S.E.

K.R

D.L.

F.P.

D.Z.

Mean

$\begin{array}{ll}475 & 59 \\ 421 & 71 \\ 463 & 74 \\ 357 & 59 \\ 396 & 52 \\ 494 & 80 \\ 434.3 & \end{array}$

$\begin{array}{cc}32 & 3 \\ 30 & 3 \\ 32 & 3 \\ 34 & 4 \\ 26 & 3 \\ 29 & 3 \\ 30.5 & \\ F(1,5)=27.98, p<.01 \\ \\ 509 & 80 \\ 433 & 56 \\ 503 & 52 \\ 377 & 60 \\ 498 & 55 \\ 499 & 69 \\ 469.8 & \end{array}$

$\mathrm{F}(2,10)=12.45, \mathrm{p}<.01$

Mean

650.8

684.0
Saccade Duration

$\begin{array}{lll}38 & 3 & 20 \\ 36 & 6 & 21 \\ 39 & 3 & 23 \\ 39 & 3 & 22 \\ 28 & 3 & 21 \\ 33 & 2 & 19 \\ 35.5 & & 21.0\end{array}$

3
3
3
2
4
3

\section{Naming Time}

$\begin{array}{llll}504 & 47 & 449 & 73 \\ 436 & 45 & 363 & 60 \\ 499 & 67 & 437 & 56 \\ 415 & 59 & 360 & 47 \\ 570 & 63 & 430 & 49 \\ 526 & 47 & 494 & 75 \\ 491.7 & & 422.2 & \end{array}$

Total Response Time $706.0 \quad 617.9$
$F(2,10)=12.52, p<.01$

$\begin{array}{cccc}29 & 6 & 36 & 6 \\ 26 & 4 & 32 & 3 \\ 32 & 3 & 36 & 3 \\ 32 & 5 & 35 & 3 \\ 22 & 3 & 30 & 4 \\ 22 & 3 & 30 & 3 \\ 27.2 & & 33.2 & \\ F(2,10)=113.44, p<.001 & & \\ 5 & & & \\ 528 & 80 & 515 & 45 \\ 441 & 56 & 462 & 71 \\ 481 & 50 & 509 & 65 \\ 391 & 57 & 420 & 43 \\ 508 & 57 & 576 & 64 \\ 482 & 68 & 566 & 49 \\ 471.8 & & 508.0 & \end{array}$

667.0

708.9

Note-Fs with 1 and 5 df represent main effects of left vs. right; Fs with 2 and 10 df represent main effects of visual angle.

main effect of task $[F(1,3)=18.11, p<.03]$ and a significant interaction of Task by Visual Angle $[F(2,6)=5.42, p<.05]$. Thus, despite the fact that in the same-different task the subjects knew they would have to move their eyes only to the right, latencies were significantly shorter in the naming task. Since knowledge of location of the target decreases latency (Hackman, 1940; Miller, 1969), the mean data in the same-different task may be underestimated with respect to the data in the naming task. Finally, the significant interaction was due to longer latencies at $1 \mathrm{deg}$ than at 3 and $5 \mathrm{deg}$ in the naming task coupled with a trend of longer latencies with increasing visual angle in the same-different task.

\section{DISCUSSION}

The results of the present experiment are consistent with data reported by Bartz (1962) in showing that total response time increases as a function of the presented target's distance from the fixation point. More importantly, however, the present study provides latency data for targets falling within visual angles that are consistent with average saccade extents in normal reading. The mean latency over all conditions in the present experiment was $178 \mathrm{msec}$, which is somewhat shorter than the average of $200 \mathrm{msec}$ (or larger) often reported by other investigators (Bartz, 1962; Miller, 1969; Robinson, et al., 1976). However, it should be noted that the targets in the prior experiments were often considerably farther from fixation $(5-40 \mathrm{deg})$ than those in the present experiment. The study by Bartz (1962) implies that, over a wide range of visual angles, latency increases as a function of target displacement. The mean latency of the present experiment is in close agreement with data reported by Dodge (1907). Unfortunately, Dodge did not differentiate between saccades to the left and to the right.

The importance of clearly differentiating between saccades to the left and right was evident in the present data. Latencies for saccades to the left were significantly longer than saccades to the right. In this respect, these data are consistent with data reported by Lesevre $(1964,1968)$ and contradict data reported by Dossetor and Papaioannou (1975). Since a high proportion of saccades in reading are made in a left-to-

Table 2

Mean Latencies (in Milliseconds) as a Function of Task and Visual Angle

\begin{tabular}{lcccc}
\hline & \multicolumn{4}{c}{ Visual Angle (Deg) } \\
& 1 & 3 & 5 & M \\
\hline Same-Different Task & 175 & 179 & 201 & 185 \\
Naming Task & 161 & 157 & 155 & 158 \\
Mean & 168 & 168 & 178 & \\
\hline
\end{tabular}


right direction, it seems reasonable that there should be shorter latencies for saccades to the right, as in the present experiment and as found by Lesevre. Reasons for Dossetor and Papaioannou's results are unclear, but, as mentioned earlier, the mean latencies they reported are unusually long even for saccades of 40 deg.

The results of the present study confirm earlier reports that task demands affect saccadic latency (Hackman, 1940). In the naming task, the latencies were much shorter than in the same-different task. In the latter task, an efficient strategy would be to leave the eyes on the fixation point for a longer period of time to gain as much information about the word as possible prior to the saccade and the display change. Presumably, the longer the latency, the more information the subject would be able to process regarding the parafoveal word. In this respect, it is interesting that there was no correlation between saccadic latency and accuracy in the samedifferent task (Rayner, 1978). In the naming task, the most reasonable strategy would be to quickly move the eyes to the word location, since the task was to name the word as rapidly as possible. The significant Task by Visual Angle interaction was probably also due to differences in strategy associated with the two tasks. In the same-different task, the farther the parafoveal word was from fixation, the more difficult it would be to get information because of acuity factors. Thus, subjects had longer latencies as the distance of the word from the fovea increased. An inverse trend was observed in the naming task such that shorter latencies were found for words further from fixation. This trend could be due to the subject's realization that little useful information could be obtained from words farther from fixation; hence, they moved their eyes as rapidly as possible. For words presented closer to fixation, however, it was possible to obtain useful information; hence, the eye tended to remain on the fixation point for slightly longer periods of time.

In summary, the results of the present experiment showed that latencies to word targets within the range that saccades are typically made in reading were $30-100 \mathrm{msec}$ shorter than these subjects' mean fixation durations when reading connected discourse. Latencies were significantly shorter for left-to-right than for right-to-left saccades; this result may be related to the fact that readers make more left-to-right saccades during reading. On the other hand, this result may be related to handedness and cerebral hemisphere function, a possibility we are currently investigating. Finally, task demands were important in determining saccadic latency.

\section{REFERENCES}

Baloh. R. W.. d Honklbia, V. Reaction time and accuracy of the saccadic eve movements of normal subjects in a movingtarget task. Aliation. Space, and Environmental Medicine, 1976. 47. $1165-1167$
Bart7, A. E. Eye-movement latency, duration, and response time as a function of angular displacement. Journal of Experimental Psychology, 1962. 64, 318-324.

Dodge, R. An experimental study of visual fixation. Psychological Review Monograph Supplement, 1907. 8(Whole No. 37).

Dossetor. D. R., \& Papaioannou, J. Dyslexia and eye movements. Language and Speech, 1975, 18. 312-317.

HaBer. R. N.. \& Hershenson, M. The psychology of visual perception. New York: Holt. Rinehart. \& Winston, 1973.

HACKMAN. R. B. An experimental study of variability in ocular latency. Journal of Experimental Psychology, 1940, 27, 546-558.

Kučera. H., \& Francis, W. N. Computational analysis of present-day American English. Providence. R.I: Brown University Press. 1967.

LESEVRE. N. Les mouvements oculaires dexploration. Etude electro-oculographique comparee denfants normaux et d'enfiants dyslexiques. Unpublished doctoral dissertation. University of Paris. 1964.

LESEVRE, N. L'organisation du regard chez des enfants d'age scolaire, lecteurs normaux et dyslexiques. Revue de Neuropsychiatric Infuntile, 1968, 16. 323-349.

Miles, W. R. Psychological studies of human variability. Psychological Monographs, 1936, 212(Whole No.).

Miller, L. K. Eye movement latency as a function of age. stimulus uncertainty, and position in the visual field. Perceptual and Motor Skills, 1969. 28, 631-636.

RAYNER. K. Foveal and parafoveal cues in reading. In J. Requin (Ed.). Attention and performance VII. Hillsdale, N.J: Lawrence Erlbaum, 1978.

RAYNER, K.. \& MCConkie, G. W. What guides a reader's eye movements? Vision Research, 1976. 16. 829-837.

Robinson, G. H., Koth, B. W., \& Ringenbach, J. P. Dynamics of the eye and head during an element of visual search. Ergonomics, 1976, 19.691-709.

Saslow, M. G. Latency for saccadic eye movement. Journal of the Optical Society of America. 1967. 57. 1030-1033.

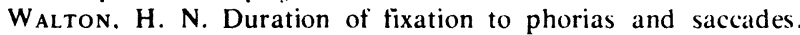
American Journal of Optometry and Archives of American Academy of Optometry, 1964, 41. 10-16.

White. C. T.. Easton, R. G.. \& Bartlett. N. R. Latency and duration of eye movements in the horizontal plane. Journal of the Optical Society of America. 1962. 52. 210-213.

WinER. B. J. Statistical principles in experimental design. New York: McGraw-Hill, 1971

Woodworth, R. S. Experimental psychology: New York: Henry Holt, 1938.

(Received for publication September 12, 1977.) 